\title{
TERAPIA PULPAR PARA LOS DIENTES DECIDUOS: UN ENFOQUE ACTUAL
}

Martha Juliana Rodriguez Gómez

Odontóloga, U. Javeriana, Odontopediatra C.E.S., Docente, U. Santo Tomás

Autor responsable de correspondecia: Dra. Martha Juliana Rodriguez G.

Correo electrónico: marthajuro@yahoo.com

Presentación realizada en el I Simposio de Actualización en Odontología Pediátrica en Bogotá,

noviembre 6 de 2004.

\begin{abstract}
RESUMEN
La terapia pulpar en dientes deciduos es uno de los procedimientos más practicados en la odontología pediátrica. El tema ha sido objeto de numerosas investigaciones; los agentes con los que se realiza han sido probados en varios estudios. En los últimos años, se ha avanzado en el campo de la formación dentinal a través de las proteinas morfogenéticas. En el futuro, puede que este sea el motivo para que se de un cambio drástico en la forma de realizar la terapia pulpar en la dentición decidua. El objetivo de este artículo es hacer una revisión sobre los tratamientos pulpares, sobre sus avances y las diferentes alternativas que se presentan en la literatura actual. [Rodríguez M]. Terapia pulpar para los dientes deciduos: Un enfoque actual. Ustasalud odontología 2004; 3: 108 - 116].
\end{abstract}

Palabras clave: Terapia pulpar, Formocresol, Proteinas morfogenéticas.

PULP THERAPY FOR PRIMARY TEETH: AN ACTUAL APPROACH

\begin{abstract}
Pulp therapy for primary teeth is a common practice in pediatric dentistry. It has been much studied and the agents used have been tested in many investigations. In recent years, there has been an advanced in the field of dentinal formation because of the morphogenetic proteins. The purpose of this paper was to review the pulp therapy, its advances and the different alternatives in the actual literature.
\end{abstract}

Key words: Pulp therapy, Formocresol, Morphogenetic proteins.

Recibido para publicaciön: 6 octubre de 2004. Aceptado para publicación: 15 de noviembre de 2004 .

\section{INTRODUCCIÓN}

A través de los años, la terapia pulpar en la dentición decidua ha sido motivo de investigación y controversia. ${ }^{1}$ Aunque existe similitud entre el complejo dentinopulpar de un diente permanente y el de un diente temporal, los objetivos del tratamiento pulpar en un diente permanente difieren en gran medida de un diente temporal. Por ejemplo, una pulpotomia, en un diente permanente, se realiza con el objetivo de causar una apexogénesis; en cambio, una pulpotomia, en un diente deciduo, se puede realizar con formocresol, un agente que no promueve la cicatrización. ${ }^{2}$ En algunas ocasiones, el "éxito" también es considerado de manera diferente. Conservar un diente deciduo, durante un año, es "éxito", mientras que conservar un diente permanente, un año, es "fracaso".
El objetivo de este documento es hacer una revisión sobre los tratamientos pulpares, que se realizan y enseñan actualmente, sobre los avances en investigación y las últimas tendencias de la terapia pulpar para los dientes deciduos.

\section{Estructura y composición del complejo dentinopulpar}

La pulpa se forma a partir de la papila dental, tejido mesenquimal, bajo el epitelio oral, capaz de ejercer un papel inductor sobre la formación del órgano del esmalte. Los estadios tempranos del desarrollo se caracterizan por la proliferación de fibroblastos y la diferenciación de los odontoblastos. El órgano joven se caracteriza por un alto contenido celular con pocas fibras y rico suministro sanguíneo. $^{3}$ 
La pulpa joven está dominada por células, que parecen disminuir en número, a medida que aumentan los vasos sanguíneos, nervios y tejido fibroso. La arquitectura de la pulpa no se parece a la de otros órganos del cuerpo. Tanto los vasos aferentes como los eferentes y los nervios entran y salen de este órgano en el mismo sitio y en varios lugares dependiendo de las raíces del diente. Durante la erupción dental, la pulpa coronal se diferencia rápidamente en una zona central, que contiene grandes vasos y nervios y una zona periférica, con un área celular rica, un área libre de células y un área dentinogénica. ${ }^{3}$

El espesor dentinal (distancia comprendida entre la unión amelodentinal y la cámara pulpar) varia entre $1.5 \mathrm{~mm}$ y $3.0 \mathrm{~mm}$, en el área dentinogénica. Esta variación depende del tipo de diente, superficie y edad de éste. Con el transcurso del tiempo, el espesor de la dentina aumenta y la velocidad, con que lo hace, disminuye. ${ }^{4}$

Sumikawa y colaboradores encontraron que cerca de la unión amelodentinal, la densidad tubular (número de túbulos $/ \mathrm{mm}^{2}$ ) parece mayor en los dientes primarios que en los permanentes. Se debe aclarar que se analizaron solo dientes anteriores. ${ }^{5}$

En los primeros molares primarios el espesor dentinal por superficie, el diámetro de los túbulos dentinales y la densidad tubular es menor en el 1/3 medio coronal en relación con los segundos molares. ${ }^{4,6}$ Además, se ha sugerido que la densidad tubular numérica tiende a disminuir de coronal a apical y con una posición más posterior del diente. ${ }^{4.6}$ Estos valores (Tabla 1) parecen tener implicaciones importantes en la adhesión de los materiales dentales, debido a su influencia en la permeabilidad dentinal. $5,7.9$

Esta permeabilidad es la responsable de la entrada de bacterias e irritantes en la pulpa. Se ha observado que en los molares primarios, la permeabilidad aumenta con la reducción del espesor dentinal, por aumento en el diámetro y en la densidad tubular.

Los avances recientes en el campo de la formación dentinal han abierto nuevas alternativas para la terapia pulpar. Se podría inducir la formación de dentina reparativa con proteínas dentinogénicas, similares a las proteínas del cuerpo humano. ${ }^{1}$ Urist observó que la matriz ósea desmineralizada estimuló la formación ósea cuando se implantó en un músculo y concluyó que la matriz ósea contenía un factor capaz de realizar una autoinducción; llamó a este factor Proteína Morfogenética Ósea (BMP)..$^{10}$

La BMP se ha relacionado con el desarrollo dental. La expresión de BMP2 se aumenta durante la diferenciación final de los odontoblastos y también induce gran cantidad de dentina reparativa sobre la pulpa. ${ }^{11,12}$

Actualmente, se optimizan las técnicas para aislar las células madre pulpares y manipular su crecimiento in vitro. De esta manera, la terapia celular con BMP2 puede volverse una realidad clínica hacia un tratamiento biológicamente regenerativo.

\section{Terapia pulpar en los dientes deciduos}

\subsection{Terapia pulpar vital}

Su objetivo es tratar los daños pulpares reversibles y mantener la vitalidad y la función pulpar. El éxito de esta clase de terapia depende del tipo y la localización del daño, la edad del diente, la modalidad de tratamiento (material para el recubrimiento) y la integridad de la cavidad que va a ser restaurada. ${ }^{13}$

Tres condiciones fisiopatológicas pueden observarse cuando el complejo dentinopulpar es afectado por una injuria en el límite dentino pulpar:

\begin{tabular}{cccc}
\hline & Superficie & Primeros molares & Segundos molares \\
\hline Promedio del & Mesial & 1,655 & 2,013 \\
espesor & Distal & 1,664 & 2,192 \\
dentinal & Lingual & 1,869 & 2,730 \\
(mm) & Vestibular & 2,430 & 3,006 \\
Promedio del diámetro tubular $(\mu \mathrm{m})$ & 0,794 & 1,0 \\
Promedio de la densidad tubular & $17,997.594$ & $25,211.317$ \\
$\quad$ (tubulos $/ \mathrm{mm}^{2}$ ) & & \\
\hline
\end{tabular}

Tabla 1. Dimensiones del espesor dentinal, diámetro de los túbulos dentinales y densidad tubular en los molares deciduos. ${ }^{3,5}$ 
1. En caso de daños leves, los odontoblastos sobreviven. La capa odontoblástica es estimulada para formar la matriz de dentina terciaria bajo el daño, mientras se forma la dentina peritubular en los túbulos dentinales. Esta dentina muestra similitudes anatómicas, bioquímicas y funcionales con la dentina primaria y secundaria y puede contrarrestar los estímulos destructores para proteger la pulpa. Representa la biosíntesis de los odontoblastos primarios, afectados por el daño. ${ }^{14}$

El propósito final de un tratamiento regenerativo es regular la biosíntesis de los odontoblastos primarios del área afectada. ${ }^{13}$

2. En daños dentinales severos, sin exposición pulpar, los odontoblastos son destruídos y se inicia la cascada de eventos inflamatorios y de cicatrización. Como parte de la cicatrización del tejido conectivo, las células pulpares proliferan y migran hacía la dentina cercana a la pulpa. ${ }^{14}$

El objetivo del tratamiento regenerativo, en este caso, sería favorecer la actividad biológica de la matriz de dentina para que pueda realizar la diferenciación de las células parecidas a los odontoblastos y reemplazar los odontoblastos primarios. ${ }^{13}$

3. La exposición pulpar muestra un potencial limitado de recuperación, especialmente, si existe infección. Inicialmente, las células pulpares migran, proliferan y elaboran nuevo colágeno en contacto con la zona necrótica tratada. Finalmente, se inicia la dentinogénesis reparativa; se forma una capa de células parecidas a los odontoblastos en asocio con la calcificación superficial y la matriz tubular mineralizada. ${ }^{15,16}$

El propósito final de un tratamiento regenerativo es inducir la diferenciación de las células parecidas a los odontoblastos en la interfase con el material de recubrimiento y regular la biosíntesis de los odontoblastos primarios, alrededor de la exposición pulpar, para reconstruir el limite dentinopulpar. ${ }^{14}$

Se han reportado éxitos en los estudios en los que la aplicación de proteínas dentinales, como la fibronectina, sobre las exposiciones pulpares estimula la creación de un puente dentinal. ${ }^{2}$ Por lo tanto, se pensaría que es mejor aplicar estas sustancias en lugar de colocar agentes químicos provenientes de los materiales dentales. Además, a los factores de crecimiento específico, especial- mente los que pertenecen a la superfamilia TGF- $\beta$, se les atribuye la habilidad de reemplazar a los odontoblastos cuando se colocan sobre el tejido pulpar. ${ }^{2}$

Así es como la aplicación de la biología molecular en la terapia pulpar vital produce la cicatrización pulpar y se considera el futuro.

La terapia pulpar vital incluye dos enfoques terapéuticos:

\subsubsection{Tratamiento pulpar indirecto.}

Se define como el procedimiento por el que se remueve el tejido cariado y se deja una delgada capa de caries en la parte más profunda de la preparación cavitaria para evitar una exposición pulpar. ${ }^{17,18}$

Se realiza sobre la base de que pocas bacterias permanecen viables en las capas más profundas de la dentina y se inactivan cuando la cavidad se sella apropiadamente. Este hecho contraindica el procedimiento a dos pasos (reapertura de la cavidad para confirmar la formación de dentina reparativa). ${ }^{19} \mathrm{Su}$ objetivo final es detener el proceso carioso, promover la formación de dentina esclerótica (aumento de la dentina peritubular), estimular la formación de dentina terciaria y remineralizar la dentina cariada. ${ }^{20,21}$

Sus indicaciones se limitan a los dientes que no tienen signos o sintomas de pulpitis irreversible. ${ }^{22.23}$ Existe cierta controversia sobre la aplicación del tratamiento pulpar indirecto en los dientes deciduos. Mathewson y Primosch sugieren que el recubrimiento indirecto solo debe realizarse en los dientes permanentes. ${ }^{23}$ Una investigación sobre el uso de esta técnica en los programas de predoctorado de los Estados Unidos mostró que la mayoría de los programas la enseñan (70\%); pero sólo el 26\% la eligen en casos de lesiones cariosas profundas. ${ }^{24}$

Según Ranly y García-Godoy, es posible que esto se deba a varias razones: la pulpotomia en los dientes deciduos no es procedimiento complicado y su costo tampoco es elevado. La delgada capa de dentina residual requiere un alto grado de juicio clínico y el comportamiento del paciente puede determinar que sea mejor una conducta que se perciba como definitiva. ${ }^{2}$

Actualmente, se investiga sobre el éxito de este tipo de tratamiento y el material ideal para realizarlo. La Tabla 2

110

Ustasalud Odontología 2004; 3: 108 - 116

Rodríguez MJ. 


\begin{tabular}{|c|c|c|c|c|c|}
\hline Autores & $n$ & Inclusión & Material & Seguimiento & Éxito (\%) \\
\hline $\begin{array}{l}\text { Aponte y col. } \\
\text { (1966) }\end{array}$ & 30 & Lesión profunda & $\mathrm{Ca}(\mathrm{OH})_{2}$ & 6 a 46 meses & 93 \\
\hline $\begin{array}{l}\text { Nirschl y Avery } \\
\text { (1983) }\end{array}$ & 18 & Lesión profunda & $\mathrm{Ca}(\mathrm{OH})_{2}$ & 6 meses & 94 \\
\hline Farooq y col. & 42 & Sin dolor & Ionómero & 2 a 7 años & 93 \\
\hline (2000) & 13 & Pulpitis reversible & & & 85 \\
\hline Falster y col. & 23 & Lesión profunda & $\mathrm{Ca}(\mathrm{OH})_{2}$ & 2 años & 83 \\
\hline (2002) & 25 & & Adhesivo & & 96 \\
\hline $\begin{array}{l}\text { Al-Zayer y col. } \\
(2003)\end{array}$ & 187 & Lesión profunda & $\mathrm{Ca}(\mathrm{OH})_{2}$ & 2 sem. a 6 años & 85 \\
\hline $\begin{array}{l}\text { Vij y col. } \\
(2004)\end{array}$ & 108 & $\begin{array}{l}\text { Presencia o no de } \\
\text { pulpitis reversible }\end{array}$ & Ionómero & 3 años & 94 \\
\hline
\end{tabular}

Tabla 2. Presentación de algunos estudios, en orden cronológico, sobre el tratamiento pulpar indirecto en dientes deciduos. ${ }^{22,25-29}$

muestra un resumen de diferentes investigaciones en las que se ha estudiado el tratamiento de recubrimiento indirecto.

Aponte y colaboradores, y Nirschl y Avery realizaron la apertura de las cavidades para conocer el estado bacteriológico de la dentina residual. Sobre este hallazgo basaron el éxito del tratamiento. ${ }^{25.26}$

En los estudios descritos se ha usado como base el hidróxido de calcio (técnica convencional) o un sistema adhesivo. La aplicación de un acondicionador ácido en el esmalte y en la dentina no ocasiona un daño pulpar irreversible, si el espesor de la dentina tiene al menos $0.5 \mathrm{~mm}$ y no hay exposición pulpar. ${ }^{30}$ Además, se ha demostrado que el pH ácido de estos agentes producen una disminución considerable de las bacterias en el tejido remanente. ${ }^{31}$

Aunque se ha observado la presencia de una "capa híbrida modificada" en la interfase resina/dentina cariada, se sabe que la adhesión de las resinas compuestas con la dentina cariada es débil. ${ }^{32}$ Por lo tanto, es aconsejable retirar todo el tejido cariado de las paredes laterales de la cavidad para asegurar un buen selle.

Al-Zayer y colaboradores observaron la influencia de los materiales restauradores en el éxito del tratamiento. Concluyeron que una obturación en amalgama tiene 7.7 más probabilidades de fracasar en comparación con una corona de acero. De los dientes tratados con corona de acero (101) sólo fallo un diente; de los trece dientes tratados con resina compuesta no falló ninguno. ${ }^{28}$

En algunos estudios se han encontrado mayores fracasos en los primeros molares deciduos. ${ }^{22,28}$ Se sugiere que se debe a su anatomía, tamaño y tiempo de erupción. Es el molar más susceptible de presentar lesiones cariosas tempranamente.

Es necesario realizar un diagnóstico adecuado y una remoción completa de la lesión en las paredes laterales para asegurar un buen selle cavitario y así disminuir el porcentaje de fracasos al realizar este tipo de tratamiento. Mientras tanto, se investiga cómo lograr la cicatrización del tejido infectado.

\subsubsection{Recubrimiento pulpar directo / pulpotomia.} 2.1.2.1Recubrimiento pulpar directo

El recubrimiento pulpar directo se define como la aplicación de un agente sobre el tejido pulpar expuesto, como resultado de la exploración de una lesión cariosa o de un trauma. ${ }^{20.2333}$ El uso de esta técnica, en los dientes primarios, ha sido muy controvertido, aunque en Estados Unidos se enseña en un $43 \%$ de los programas y se elige en un $34 \%$ de los casos, que hipotéticamente presentan la situación clínica adecuada. ${ }^{24}$

Estadísticamente se ha observado que el recubrimiento pulpar directo es menos exitoso comparado con el tratamiento pulpar indirecto o la pulpotomia. ${ }^{34}$ Las razones incluyen un alto potencial de reabsorción interna, calcificaciones, inflamación pulpar crónica, necrosis y afección intrarradicular. ${ }^{18,35}$ Ranly y García-Godoy difieren de la posición según la cual el hidróxido de calcio, usado en el recubrimiento pulpar directo, puede causar reabsorción interna. Sugieren que el área de la superficie del tejido en contacto con el material es pequeña, en comparación con el volumen de tejido remanente. ${ }^{2}$ Turner y colaboradores tampoco encontraron 


\begin{tabular}{|c|c|c|c|c|c|c|}
\hline Autores & $n$ & Inclusión & Material & Seguimiento & $n$ & Puente dentinal \\
\hline \multirow[t]{2}{*}{$\begin{array}{l}\text { Turner y col. } \\
(1987)\end{array}$} & 28 & \multirow[t]{2}{*}{$\begin{array}{l}\text { Caninos } \\
\text { sanos }\end{array}$} & $\begin{array}{l}\text { Life } \\
\text { Dycal }\end{array}$ & 7 días & 27 & $\begin{array}{l}\text { > Rta. inflamatoria } \\
\qquad \mathrm{Ca}(\mathrm{OH})_{2}\end{array}$ \\
\hline & 64 & & $\begin{array}{l}\mathrm{Nu} \text { - Cap } \\
\mathrm{Ca}(\mathrm{OH})_{2}\end{array}$ & 63 dias & 64 & $\begin{array}{l}>\text { Espesor } \\
\mathrm{Ca}(\mathrm{OH})_{2}\end{array}$ \\
\hline \multirow{3}{*}{$\begin{array}{l}\text { Cehreli y col. } \\
(2000)\end{array}$} & 7 & \multirow{3}{*}{$\begin{array}{c}\text { Molares } \\
\text { sanos }\end{array}$} & Vitremer & 60 dias & 7 & $(-) 4$ \\
\hline & 7 & & Dyract & & 7 & $(-) 4$ \\
\hline & 7 & & Compoglass & & 7 & $\Leftrightarrow 6$ \\
\hline
\end{tabular}

Tabla 3. Presentación de algunos estudios, en orden cronológico, sobre el tratamiento pulpar directo en dientes deciduos. ${ }^{35,36}$

reabsorción interna en los caninos deciduos tratados con recubrimiento pulpar directo, aunque el tiempo de evaluación de su estudio fue muy corto (Tabla 3). ${ }^{36}$

El hidróxido de calcio ha sido el material más usado en los recubrimientos pulpares, por inducir la formación de un puente dentinal. ${ }^{2.18,33,37,38}$ Sin embargo, se ha observado que este puente dentinal es permeable y no constituye un selle efectivo y permite el paso bacteriano. ${ }^{36}$

Actualmente, se investiga el uso de los sistemas adhesivos de últimas generaciones. Estos materiales crean una zona híbrida, que resiste el ataque ácido, proveen un buen selle y favorecen la exclusión bacteriana. ${ }^{33,35,39}$ Además de estas ventajas, los adhesivos dentinales pueden trabajar en ambientes húmedos, lo que disminuye una lesión por deshidratación. Sin embargo, es necesario que estos materiales no sean citotóxicos; como minimo deben ser neutrales para aplicarse sobre células vivas. ${ }^{2}$

Son pocos los estudios reportadoś, que usan sistemas adhesivos, sobre la pulpa de los dientes deciduos. Cehreli y colaboradores encontraron zonas de inflamación crónica y ausencia de puente dentinal en la mayoría de las muestras, a pesar de que los molares evaluados eran sanos, y su potencial de cicatrización se supone que es mayor. Parece ser que el monómero que alcanza el tejido pulpar es el responsable de tales reacciones inflamatorias ${ }^{35}$ La persistencia de una respuesta inflamatoria crea un ambiente desfavorable para la diferenciación de células "parecidas a los odontoblastos", que serían las responsables de la secreción de la matriz dentinal. ${ }^{30}$ Por otra parte, Mantenilli y colaboradores sugieren que la ausencia de puente dentinal se debe a la apoptosis de las células, que intervienen en la cicatrización pulpar y en la regeneración dentinal. ${ }^{40}$
Es una falacia suponer que, únicamente, las evidencias clínicas y radiográficas demuestran la biocompatibilidad de un material dental y/o el éxito de un tratamiento ya que los hallazgos histopatológicos, en numerosas ocasiones, no corresponden con las observaciones clínicas. Por lo tanto, se concluye que el recubrimiento pulpar directo en los dientes primarios debe restringirse sólo a exposiciones pulpares accidentales cuando las condiciones clínicas son favorables, como un campo aséptico...18,30344,37

\subsubsection{Pulpotomía}

Este tratamiento ha sido objeto de investigación y controversia durante varios años. La pulpotomia puede clasificarse, según el objetivo del tratamiento en:

- Desvitalización: Formocresol, electrocirugía, láser.

- Preservación: Óxido de zinc eugenol, glutaraldehído, sulfato férrico, pasta Guedes-Pinto. ${ }^{37}$

- Regeneración: Hidróxido de calcio, Mineral Trióxido Agregado (MTA), BMP, vidrio bioactivo.

El formocresol fija el tejido radicular infectado y afectado de modo que una inflamación crónica reemplaza una inflamación aguda. ${ }^{2}$ Su éxito clínico ha asegurado su permanencia como agente de elección, de acuerdo con tres investigaciones realizadas en los programas de predoctorado de odontopediatría de Estados Unidos, en 27 programas de odontología de algunas universidades brasileras y entre los especialistas de odontopediatría del Reino Unido (Tabla 4). $\cdot^{2,41,42}$

A pesar de ser el agente más usado, los resultados de los estudios con formocresol y sus efectos secundarios han sido motivo de controversia. Cárdenas considera que tales discusiones se originan por el uso errático del medicamento, por una falla en el diagnóstico o por una mala técnica. ${ }^{44}$ 


\begin{tabular}{lccc}
\hline PULPOTOMIA & $\begin{array}{c}\text { R. Unido }(*) \\
n: 179^{*}\end{array}$ & $\begin{array}{c}\text { E. Unidos } \\
n: 53\end{array}$ & $\begin{array}{c}\text { Brasil(*) } \\
n: 27\end{array}$ \\
\hline Formocresol & 17.9 & 22.6 & 22 \\
Formocresol diluido & 66.5 & 71.7 & 41 \\
Hidróxido de Calcio & 11.7 & & 7 \\
Paraformaldehido & 12.3 & & \\
Sulfa to ferrico & 2.8 & 3.8 & \\
$\begin{array}{l}\text { Pasta Guedes - Pinto } \\
\text { Glutaraldehido }\end{array}$ & & & 19 \\
Otros & 3.4 & 1.9 & 7 \\
\hline
\end{tabular}

'Las respuestas de algunos especialistas no fueron exclusivas para un solo agente.

Tabla 4. Uso de diferentes agentes para pulpotomia en dientes deciduos. ${ }^{24,41,42}$

Por varios años se usó el hidróxido de calcio como una alternativa. Sin embargo, no se obtuvo el éxito esperado; los estudios reportaban una alta incidencia de reabsorción interna en los dientes deciduos, posiblemente, por la formación de un coágulo entre el material y el tejido pulpar. ${ }^{244}$ Por tal motivo, se han investigado otros agentes (Tabla 5).

El sulfato férrico fue investigado, originalmente, como un agente hemostático que preparaba la zona para la aplicación del hidróxido de calcio. De esta manera, se controlaba la hemorragia y se mejoraba la eficacia del hidróxido de calcio. ${ }^{1}$ En algunos estudios se observó un éxito clínico y radiográfico similar al reportado con el formocresol. ${ }^{45,45}$ Sin embargo, Burnett y Walker encontraron valores por debajo de lo esperado. Esto podría deberse a que los procedimientos fueron realizados por varios operadores; es posible que el diagnóstico no fuera el más acertado. ${ }^{48}$

La electrocirugía ha ganado popularidad, por ser un tratamiento no farmacológico, fácil de usar y los resultados, favorables. ${ }^{50.51}$ Los estudios en humanos, con estos agentes, muestran un seguimiento limitado, y las muestras, en algunas ocasiones, son pequeñas. Además, es de anotar que el éxito, también se debe a un diagnóstico correcto y a un selle coronal adecuado

Los adhesivos dentinales que se han usado para recubrimientos directos podrían ser usados para pulpotomias. Se supone que la respuesta pulpar sería más favorable, ya que en este procedimiento se elimina todo el tejido enfermo y el material estaría en contacto con tejido sano. Aunque no se conocen estudios en esta área, puede ser que la tecnología progrese en este campo. ${ }^{2}$

\begin{tabular}{|c|c|c|c|c|c|c|c|}
\hline Autores & $n$ & Material & $\begin{array}{c}\text { Seguimiento } \\
\text { (meses) }\end{array}$ & $n$ & $\begin{array}{l}\text { Clin. } \\
(\%)\end{array}$ & $\begin{array}{l}R x . \\
(\%)\end{array}$ & Hx." \\
\hline Fuks y col. & 58 & Sulfato férrico & 6 a 34 & 55 & \multicolumn{2}{|c|}{92.7} & \\
\hline (1997) & 38 & Formocresol diluido & & 37 & \multicolumn{2}{|c|}{83.8} & \\
\hline $\begin{array}{l}\text { Smith y col. } \\
(2000)\end{array}$ & 242 & Sulfato férrico & 25 a 36 & - & 99 & 80 a 74 & \\
\hline \multirow{2}{*}{$\begin{array}{l}\text { Eidelman y col. } \\
(2000)\end{array}$} & 17 & MTA & 6 a 30 & 17 & 100 & 100 & \\
\hline & 15 & Formocresol & & 15 & 100 & 94.1 & \\
\hline \multirow{3}{*}{$\begin{array}{l}\text { Burnett y Walter } \\
(2002)\end{array}$} & 83 & Formocresol & 21 a $36 ?$ & 83 & & 81 & \\
\hline & 45 & Sulfato férrico & & 45 & & 76 & \\
\hline & 74 & Formo + Sulfato & & 74 & & 69 & \\
\hline \multirow{2}{*}{$\begin{array}{l}\text { Sasaki y col. } \\
(2002)\end{array}$} & ¿33? & $\mathrm{Ca}(\mathrm{OH})_{2}$ & 6 a 34 & $\measuredangle 33$ & 94.1 & 88.2 & \\
\hline & & $\mathrm{Ca}(\mathrm{OH})_{2}+$ electro & & $?$ & 93.8 & 93.8 & \\
\hline Dean y col. & 25 & Formocresol & 5 a 25 & 25 & 100 & 92 & \\
\hline (2002) & 25 & Electrocirugia & 6 a 31 & 25 & 96 & 84 & \\
\hline Rivera y col. & 40 & Formocresol & 1 a 6 & 40 & \multicolumn{2}{|c|}{92.5} & \\
\hline \multirow[t]{3}{*}{ (2003) } & 40 & Electrocirugia & & 40 & \multicolumn{2}{|c|}{92.5} & \\
\hline & 24 & MTA gris & 1 a 12 & 19 & 100 & 100 & \\
\hline & 24 & MTA blanco & & 16 & 80 & 80 & \\
\hline Agamy y col. & 24 & Formocresol & & 18 & 90 & 90 & \\
\hline \multirow[t]{3}{*}{$(2004)$} & 5 & MTA gris & 1 a 6 & 5 & & & $(+)$ \\
\hline & 5 & MTA blanco & & 5 & & & $(+)$ \\
\hline & 5 & Formocresol & & 5 & & & $(-)$ \\
\hline
\end{tabular}

* Formación de puente dentinal.

Tabla 5. Presentación de los estudios, en orden cronológico, sobre pulpotomias en molares deciduos. 
Se necesitaría más investigación sobre estos materiales aunque, actualmente, la atención se dirige hacia los agentes, que puedan causar la regeneración pulpar. Los estudios con MTA son promisorios; generalmente, presentan excelentes resultados. ${ }^{47,52}$ Sin embargo, se ha avanzado enormemente en el desarrollo de las proteínas morfogenéticas óseas (BMP), que se obtienen a través del desarrollo de la biología molecular. Estas tienen propiedades para inducir la formación ósea, y tendrían grandes implicaciones clínicas si estimularan la formación dentinal. ${ }^{1.2}$

El nombre de las BMP es un término genérico de esta familia. Por lo tanto, ha cambiado por la familia DVR (relativo a decapentaplegic- $\mathrm{Vg}$ ), basándose en los dos miembros identificados: Drosophila y Xenopus Vg1. La familia DVR pertenece a la superfamilia de los factores transformadores del crecimiento (TGF- $\beta$ ). ${ }^{1,2}$

Sería un gran logro de la ciencia sí estos factores de crecimiento se pudieran usar, rutinariamente, en la clínica para inducir la formación de puentes dentinales sanos, que aislaran el tejido pulpar. De esta manera, la pulpa radicular de los dientes primarios estaría libre de inflamación.

\subsection{Terapia pulpar no vital}

La terapia endodóntica de los dientes primarios se ha usado cuando se considera que hay inflamación o necrosis de la pulpa radicular. No es una terapia aceptada en todos los países. En Escandinavia, los dientes con necrosis pulpar son extraídos; no se considera la terapia endodóntica en dientes deciduos, por las dificultades en la instrumentación, riesgo de lesionar el germen del permanente y porque aún no se ha encontrado un material de obturación ideal. ${ }^{53}$

En Estados Unidos, se usa la pasta de óxido de zinc-eugenol en un 90\%; en Brasil, se usa la pasta Guedes-Pinto en un $48 \%$, seguido del óxido de zinc-eugenol en un $19 \% .{ }^{24,41}$

En 1981, Guedes-Pinto y colaboradores investigaron varios medicamentos para el tratamiento endodóntico de los dientes deciduos con necrosis pulpar. Se formuló una pasta de obturación de los conductos radiculares que contenía Rifocort ${ }^{\circledast}$ (Rifampicina sódica y acetato de prednisolona), paramonoclorofenolalcanforado y yodoformo. Se realizó el seguimiento clínico y radiográfico de 45 dientes deciduos (anteriores y posteriores) durante dos años y se obtuvo un $97.7 \%$ de éxito. Esta pasta paso a ser llamada por el nombre del primer investigador. Posteriormente, se realizaron más estudios tanto en animales como en humanos; el índice de éxito fue alto. ${ }^{54}$

Hace poco se desarrolló una nueva preparación, Vitapex que es una mezcla de yodoformo (40.4\%), hidróxido de calcio $(30.3 \%)$ y silicona $(22.4 \%)$. Los estudios preliminares sugieren buenos resultados clínicos y radiográficos. ${ }^{55,56}$

\section{CONCLUSIONES}

En cualquier tipo de terapia pulpar es definitivo realizar un diagnóstico acertado y un buen selle cavitario.

En un futuro, la terapia pulpar vital tendrá como objetivo regular la biosintesis de los odontoblastos primarios para producir una verdadera cicatrización pulpar.

En cualquier caso, las nuevas estrategias de tratamiento deben ser evaluadas cuidadosamente en estudios bien diseñados de manera que se tengan en cuenta todas las posibles variables clínicas que puedan existir:

\section{BIBLIOGRAFIA}

1. Ranly DM. Pulpotomy therapy in primary teeth: new modalities for old rationales. Pediatr Dent 1994; 16: 403 - 409.

2. Ranly DM, Garcia-Godoy E. Current and potential pulp therapies for primary and young permanent teeth. J Dent 2000; 28: 153 - 161.

3. Avery J. Structural element's of the young normal human pulp. Oral Surg 1971; 22: $113-125$.

4. Castillhos $\mathrm{H}$, Chevitarese $\mathrm{O}$. A comparative study of dentin thickness of primary human molars. J Clin Pediatr Dent 2003; 27: 277 - 281.

5. Sumikasa D, Marshall G, GeeL, Marshall S. Microstructure of primary tooth dentin. Pediatr Dent 1999; 21: $439-444$.

6. Castillhos H, Chevitarese O. Density and diameter of dentinal tubules of first and second primary human molars - comparative scanning electron microscopy study. J Clin Pediatr Dent 2002; 26: 297 - 304.

7. Koutsi V, Noomam RG, Horner JA, Simpson MD, Matthews WG, Pashley DH. The effect of dentin depth on the permeability and ultrastructure of primary molars. Pediatr Dent 1994; 16: 29 - 35.

8. Costa LR, Watanabe IS, Kronka MC, Silva MP. Structure and microstructure of coronary dentin in non erupted human deciduous incisor teeth. Braz Dent J 2002; 13: 170 - 174. 
9. Costa LR, Watanabe IS, Kronka MC. Coronal dentinal tubules of nonerupted deciduous incisors. Pesqui Odontol Bras 2002; 16: 12 - 17 .

10. Urist M. Bone formation by autoinduction. Science 1965; 150: 893 -899 .

11. Nakashima $\mathrm{M}$. Induction of dentin formation on canine amputated pulp by recombinant human bone morphogenetic protein (BMP)-2 and -4. J Dent Res 1994; 73: 1515 - 1522.

12. Iohara K, Nakashima M, Ito M, Ishikawa M, Naksima A, Akamine A. Dentin regeneration by dental pulp stem cell therapy with recombinant human bone morphogenetic protein 2. J Dent Res 2004; 83: $590-595$.

13. Tziafas $D$. The future role of a molecular approach to pulp dentinal regeneration. Caries Res 2004; 38: $314-320$.

14. Smith AJ. Pulpal responses to caries and dental repair. Caries Res 2002; 36: $223-232$.

15. Schroder U. Effects of calcium hydroxide-containing agent on pulp cell migration, proliferation and differentiation. J Dent Res 1985; 64: $541-548$.

16. Cvek M, Grannath L, Cleaton-Jones P, Austin J. Hard tissue barrier formation in pulpotomized monkey teeth capped with cyanoacrylate or calcium hydroxide for 10 to 60 minutes. J Dent Res 1987; 66: 1166 1174.

17. American Academy of Pediatric Dentistry. Guidelines for pulp therapy for primary and Young permanent teeth. Pediatr Dent (Reference Manual) 2003; 25: 87-91.

18. Fuks A, Eidelman E. Pulp therapy in primary dentition. Curr Opin Dent 1991; 1: $556-563$.

19. Bjorndal L, Larsen T, Thylstrup A. A clinical and microbiological study on deep carious lesions during stepwise excavation using long treatment intervals. Caries Res 1997; 31: 411 - 417.

20. Fuks A. Pulp therapy for the primary and young permanent dentitions. Dent Clin North Am 2000; 44: 571 - 595.

21. Tziafas D, Smith AJ, Lesot H. Designing new treatment strategies in vital pulp therapy. J Dent 2000; 28: $77-92$.

22. Farooq NS, Coll JA, Kuwabara A, SheltonP. Success rates of Formocresol pulpotomy and indirect pulp treatment in the treatment of deep dentinal caries in primary teeth. Pediatr Dent 2000; 22: 278 - 286.

23. Mathewson RJ, Primosch RE. Pulp treatment. En: Mathewson RJ, Prismosch RE. Fundamentals of pediatric dentistry. 3rd ed. Chicago: Quintessence; 1995. p. 257-284.

24. Primosch R, Glomb T, Jerrel R. Primary tooth pulp therapy as taught in predoctoral pediatric dental programs in the United States. Pediatr Dent 1997; 19: 118 - 122.
25. Aponte AJ, Hartsook J, Crowley M. Indirect pulp capping success verified. J Dent Child 1966; 33: 164 - 166.

26. Nirschl RF, Avery DR. Evaluation of a new pulp capping agent in indirect pulp therapy. J Dent Child 1983; 50: 25 - 30 .

27. Folster C, Araujo F, Straffon L, Nör J. Indirect pulp treatment: in vivo outcomes of an adhesive resin system vs. calcium hydroxide for protection of the dentin-pulp complex. Pediatr Dent 2002; 24: 241 - 248.

28. Al-Zayer M, Straffon 1, Feigal R, Welch $\mathrm{K}$. Indirect pulp treatment of primary posterior teeth. A retrospective study. Pediatr Dent 2003; 25: $29-36$.

29. Vij R, Coll J, Sheiton P, Farooq N. Caries control and other variables associated with success of primary molar vital pulp therapy. Pediatr Dent 2004; 26: $214-220$.

30. Costa CA, Hebling J, Hanks CT. Current status of pulp capping with dentin adhesive systems. A review. Dent Mater 2000; 16: 188 - 197.

31. Settembrini L, Boylan R, Strassler H, Scherer W. A comparison of antimicrobial activity of etchants used for total-etch technique. Oper Dent 1997; 22: $84-88$.

32. Ribeiro CC, Baratieri LN, Perdigao J, Baratieri NM, Ritter AV. A clinical, radiographic, and scanning electron microscopic evaluation of adhesive restorations on carious dentin in primary teeth. Quintessence Int 1999; 30: 591 - 599.

33. Kopel H. The pulp capping procedure in primary teeth "revisited》. J Dent Child 1997; 64: 327 - 333.

34. UK National Clinical Guidelines in Paediatric Dentistry. Int J Paediatr Dent 2000; 10: $248-252$.

35. Cehreli Z, Turgut M, Olmez S, Dagadeviren A, Atilla P. Short term human primary pulpal response after direct pulp capping with fourth generation dentin adhesives. J Clin Paediatr Dent 2000; $25: 65-71$.

36. Turner C, Courts F, Stanley H. A histological comparison of direct pulp capping agents in primary canines. J Dent Child 1987; 54: 423-428.

37. Guedes-Pinto AC. Tratamento endodontico em dentes deciduos. En: Guedes-Pinto AC. Odontopediatria. $7 \mathrm{ma}$ ed. Sao Paulo: Editora Santos; 2003. p. 553 - 573.

38. Stanley H. Pulp capping: Conserving the dental pulp - Can it be done? Is it worth it? Oral Surg Oral Med Oral Pathol 1989; 68: 628 639.

39. Nakabayashi N, Pashley DH. Hybridization of dental hard tissues. Quintessence Publ., 1998.

40. Mantenilli MG, Botero TM, Yaman P, Dennison JB, Hanks CT, Nör JE. Adhesive resin induces apoptosis and cell-cycle arrest of pulp cells. J Dent Res 2003; 82: 592 - 596. 
41. Kramer P, Faraco I, Feldens CA. Estado Atual da terapia pulpar nas universidades brasileiras - Pulpotomia e pulpectomia em dentes decíduos. Jornal Brasileiro de Odontopediatria \& Odontologia da Bebe 2000; 3: $222-230$.

42. Hunter ML, Hunter B. Vital pulpotomy in the primary dentition: attitudes and practices of Specialists in paediatric dentistry practicing in the United Kingdom. Int J Paediatr Dent 2003; 13: 246 - 250.

43. Ranly DM. Formocresol toxicity. Current knowledge. Acta Odontologica Pediátrica 1985; 5: 93 - 98.

44. Cárdenas D. Terapia pulpar En: Cárdenas D. Odontología Pediátrica. 3ra ed. Medellin: Corporación para la Investigación Biológica; 2003. p. 224-244.

45. Fuks A, Holan G, Davis J, Eidelman E. Ferric sulfate versus dilute formocresol in pulpotomized primary molars: long-term follow up. Pediatr Dent 1997; 19: 327 - 330 .

46. Smith NL, Seale NS, Nunn ME. Ferric sulfate pulpotomy in primary molars: A retrospective study. Pediatr Dent 2000; 22: $192-199$.

47. Eidelman E, Holan G. Fuks A. Mineral trioxide aggregate vs. formocresol in pulpotomized primary molars: a preliminary report. Pediatr Dent 2001; 23: $15-18$.

48. Burnett S, Walker J. Comparison of ferric sulfate, formocresol, and a combination of ferric sulfate/formocresol in primary tooth vital pulpotomias: A retrospective radiographic survey. J Dent Child 2002; 69: $44-48$

49. Sasaki H, Ogawa T, Koreeda M, Ozaki T, Sobue S, Ooshima T. Electrocoagulation extends the indication of calcium hydroxide pulpotomy in the primary dentition. J Clin Pediatr Dent 2002; 26: $275-278$.

50. Dean JA, Mack RB, Fulkerson BT, Sanders BJ. Comparison of electrosurgical and formocresol pulpotomy procedures in children. Int J Paediatr Dent 2002; 12: $177-182$.

51. Rivera N, Reyes E, Mazzaoui S, Moron A. Pulpal therapy for primary teeth: Formocresol vs. electrosurgery: A clinical study. J Dent Child 2003; 70: $71-73$.

52. Agamy HA, Bakry NS, Mounir MMF, Avery D. Comparison of mineral trioxide aggregate and formocresol as pulp-capping agents in pulpotomized primary teeth. Pediatr Dent 2004; 26: 302 - 309 .

53. Koch G, Modeér T, Poulsen S, Rasmussen R. Endodontics. En: Koch G, Modeér T, Poulsen S, Rasmussen R. Pedodontics-a clinical approach. Munksgaard; 1992. p. 185 - 210.

54. Guedes-Pinto AC. Comunicaciön personal. Sao Paulo; 2003.

55. Nurko C, García-Godoy E. Evaluation of a calcium hydroxide/ iodoform paste (Vitapex(r)) in root canal therapy for primary teeth. J Clin Pediatr Dent 1999; 23: 289 - 294.
56. Nurko C, Ranly D, García-Godoy F, Lakshmyya K. Resorption of a calcium hydroxide/iodoform paste (Vitapex(r)) in root canal therapy for primary teeth: A case report. Pediatr Dent 2000; 22: 517 - 520 .

\section{Especialización en Odontopediatría \\ ODONTOLOGIAA INFANTIL \\ Servicios de Odontopediatría y Ortodoncia Preventiva \\ CALIDAD A BAJO COSTO}

Campus de Floridablanca, Clinicas Odontológicas $\mathrm{Km} .6$ a Floridablanca

Teléfono: 6800801 ext. $2121-2433$

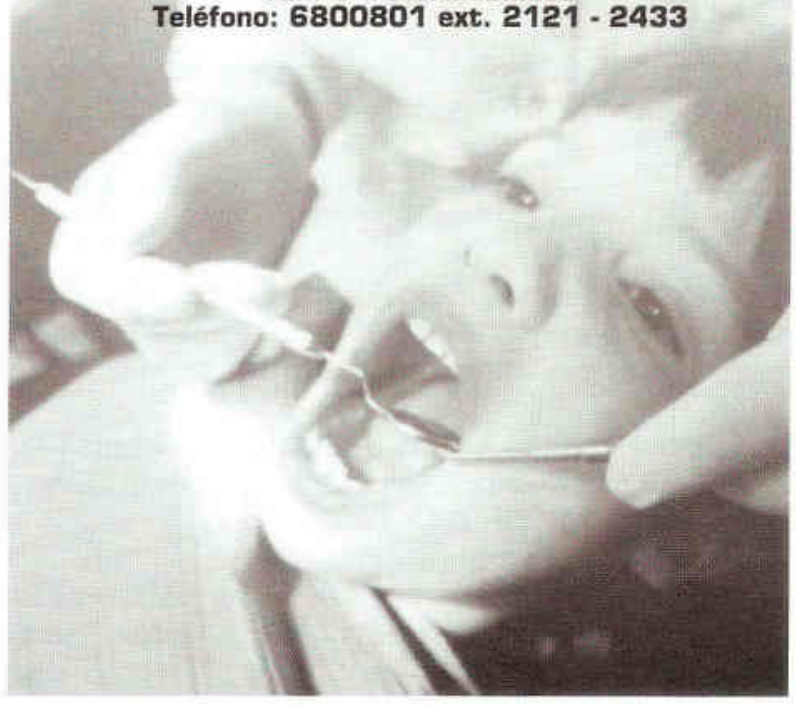

116

Ustasalud Odontología 2004; 3: 108 - 116

Rodriguez $M J$. 